\title{
Review for good platelet-rich plasma procedure in cosmetic dermatology and surgery
}

\author{
Moon Hee Kim, MD, MS', Hyeon Seob Byeon, MD² \\ ${ }^{1}$ Department of Cosmetic Medicine, GC iMED, Seoul, Rep. of Korea, ${ }^{2}$ Zen Clinic, Zen medical Corporation, Tokyo, Japan
}

\begin{abstract}
Autologous platelet-rich plasma (PRP) is a type of platelet concentrate that has been used as an adjuvant therapeutic in the field of dental and orthopedics as well as a regenerative cosmetic medicine and surgery worldwide. Recently, the paradigm for plateletmediated therapy has shifted from conventional transfusion to regenerative and immune modulating therapeutics. Technological advancements have enabled cutting-edge research to understand the mechanism of platelet activation, platelet-derived extracellular vesicles, microRNAs, protein synthesis as well as target regulation function. Although there is increasing focus on the clinical use of platelets in tissue engineering as a source of growth factors and scaffolds as well as its use in combination with various type of stem cells and other scaffold materials or for pure non-cellular therapeutic materials, in reality, there is lack of standardization of the preparation process including the devices, nomenclature of products, and parameters for product adequacy, even for autologous use. The main reason behind this is the fact that platelets are not typical cell-based materials and they have a wide range of functional variation according to the patient's condition. Moreover, there are legal issues regarding the medical act in each country depending on their policy. Therefore, the present study aimed to review the latest paradigm shift and the stance regarding PRP therapy and to offer suggestions check lists for quality management of PRP procedures to ensure effective clinical results.
\end{abstract}

Keywords: extracellular vesicles; platelet-derived growth factors; platelet-rich plasma; PRP preparation; quality assured procedure; regeneration

\section{Platelets as bio-engineering materials}

\section{Characteristics of platelets and platelet-rich plasma}

Clinicians, who are willing to conduct platelet-rich plasma (PRP) or PRP related product therapy, should know the important aspects of platelets as regenerative bio-sources for their adequate use. The three main functions of platelets are coagulation, immune modulation, and tissue repair. In addition, the platelets in PRP provide two main elements; "growth factors (GFs) and scaffold" for tissue repair except "cell" among the tissue regeneration triad [1]. In this review, we attempt to focus on "tissue repair function" of platelets in the field of cosmetic der- matology and surgery.

Platelets are small fragments of the cytoplasm of megakaryocytes formed in the bone marrow and their size ranges from approximately 5 to $12 \mu \mathrm{m}^{3}$. The average platelet count ranges from 150 to $400 \times 10^{3} / \mu \mathrm{l}$ of circulating blood, and their in vivo life span is approximately 8 to 10 days before they are cleared by the reticuloendothelial system. Although platelets contain some intracellular organelles such as mitochondria and endoplasmic reticulum fragments, they lack a nucleus and hence, cannot divide into two daughter cells (Fig. 1) [2]. In brief, this means that they cannot proliferate and differentiate or dedifferentiate when used in cell engineering. However, even though they lack 


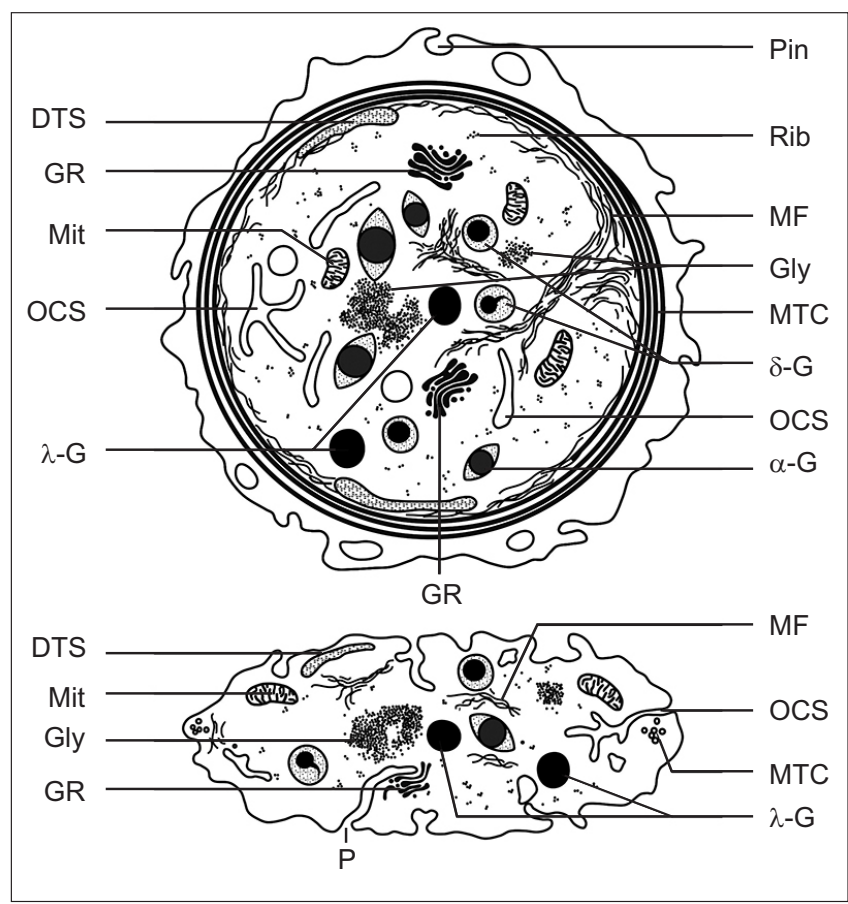

Fig. 1. A scheme of a platelet in the equatorial plane (upper image) and in cross section (image at the bottom). DTS, dense tubular system; Gly, glycogen; $\alpha$-G, $\alpha$-granules; $\delta$-G, $\delta$-granules or dense bodies; $\lambda$-G, $\lambda$-granules or lysosomes; $G R$, Golgi remnants; MF, microfilaments; Mit, mitochondria; OCS, open canalicular system; P, pores of the OCS; Rib, ribosomes; MTC, microtubular coil. Reused from Neumüller J, et al. (The transmission electron microscope theory and applications. 2015. p. 255-84) [2].

genomic DNA, the platelets inherit a limited but diverse array of functional coding or non-coding RNAs and translational machinery from their parent megakaryocytes that enables them to synthesize proteins, which suggests that post-transcriptional gene regulation and activator induced modulation can occur [3].

Platelets play a critical role in tissue repair and regeneration as they are highly responsive and secretory [4]. They can regulate fundamental mechanisms involved in the tissue healing process including cellular migration, proliferation, and angiogenesis. Activated platelets release a whole range of chemokines and promote recruitment, adhesion, and proliferation of adult stem cells. In addition, there is increasing evidence indicating that the regulation of the balance between apoptosis and cell survival, which determines the fate of the injured tissues, is controlled by platelets (Fig. 2) [5].

The most conspicuous organelles in platelet are the secretory granules. The three major granule types in platelets are dense granules, $\alpha$-granules, and lysosomes and those carry distinct cargos and vary in biogenesis, trafficking, and exocytosis. Among them, the $\alpha$-granules are the most abundant organelle in plate- lets (40 to 80 per platelet) and contain a plethora of proteins that comprise the bulk of the platelet secretion. The $\alpha$-granules, which are formed in megakaryocytes in the bone marrow, release GFs and have direct effects on the stem cells (Table 1) [6]. These granules are formed in the megakaryocytes, specifically in the trans-Golgi network and early endosomes, before being transported into the platelets. These granules mature in multivesicular bodies (MVB), and this maturation process continues in the circulating platelets through synthetic and endocytic pathways (Fig. 3) [7]. When the platelets are activated by various types of stimuli or even in case of basal vesicle secretion, the cargoes stored in the platelet granules are released, and the rates and extent of the release depend on the type of activator and the activation strength.

Platelets or platelet-derived GFs can be obtained from whole blood or platelet apheresis. In addition, they can be acquired from autologous or allogeneic pools. Currently, the apheresis platelets or pooled allogeneic platelet concentrate (PC) are used for Good Manufacturing Practice (GMP)-grade manufacture of human platelet lysate (PL) for preclinical cell propagation, which has been most commonly used for propagation of mesenchymal stem cells (MSC) and endothelial progenitors for more than a decade [8]. For clinical practice, autologous PRP or PRP derived products from whole blood are preferred for various reasons $[9,10]$.

Depending on the device and the technique used for preparing PRP, they can contain variable amounts of platelets, red blood cells (RBCs), white blood cells (WBCs), and plasma. The term PRP can be defined as the volume fraction of the blood plasma, which has a higher concentration of platelets than the baseline serum level. However, it has been suggested that approximately 1,000 to $1,500 \times 10^{3} / \mu$ of platelets are suggested as the adequate cut-off $[11,12]$. These levels are 3 to 5 times greater than the physiological concentration [13] as well as relevant to the American Association of Blood Banks (AABB) guideline, i.e., $\geq 5.5 \times 10^{10}$ platelet in $50 \mathrm{ml}$ whole blood derived PC (source of human PL) [14]. When platelets are present at concentrations of over $5,000 \times 10^{3} / \mu \mathrm{l}$, they can inhibit stem cells proliferation and differenciation [15].

In the PRP, there should be as few RBCs as possible. AABB permits only $<0.5 \mathrm{ml}$ of RBCs in $50 \mathrm{ml}$ of PC [13]. RBCs can adversely affect the platelet function by altering the local $\mathrm{pH}$, suppressing proliferation and stimulating apoptosis of fibroblasts and other stromal cells [16]. In addition to platelets, the PRP contains a number of different cells such as neutrophils, monocytes, endothelial cells, keratinocytes and MSCs [1]. These cells 


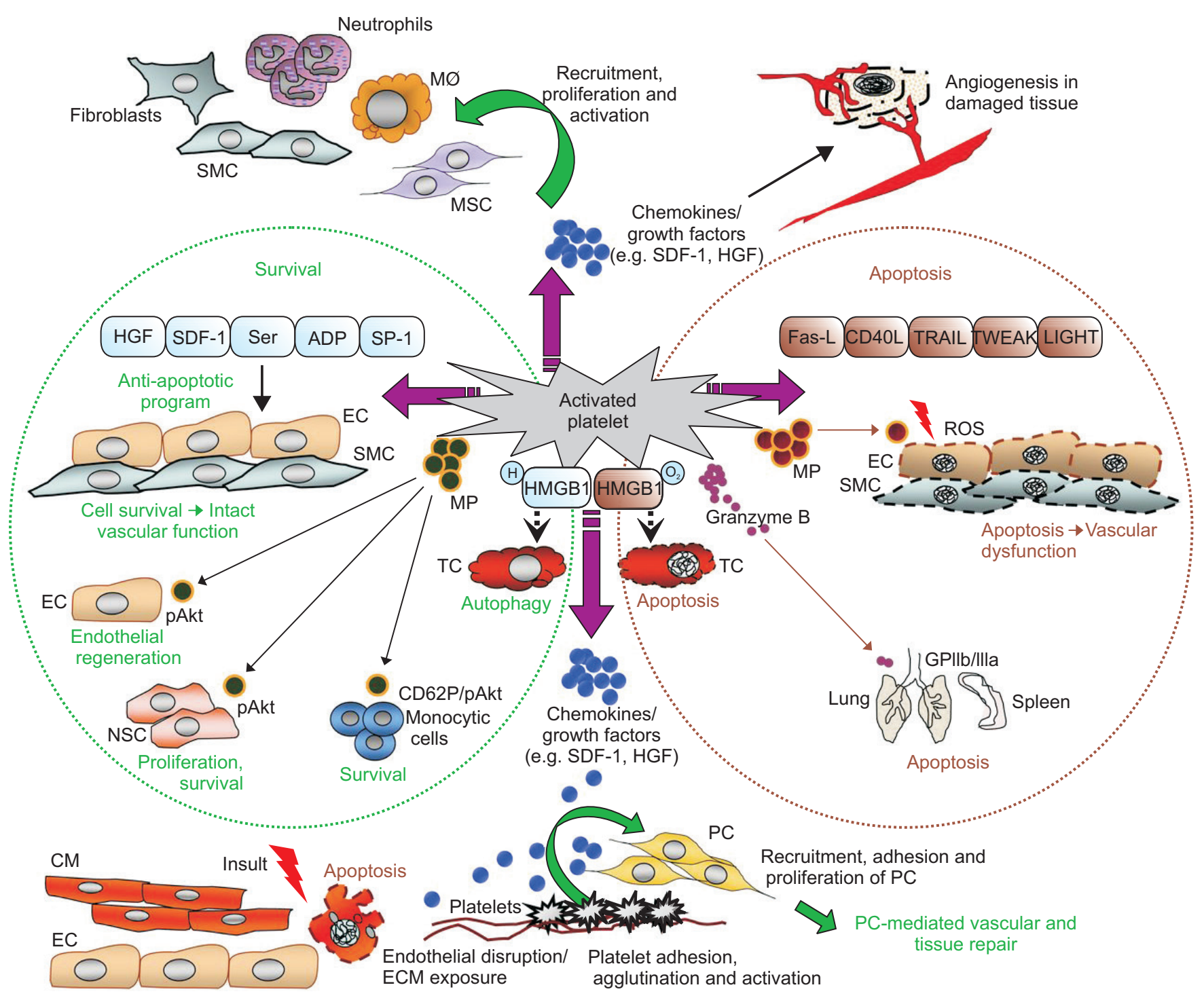

Fig. 2. Mechanisms governing platelet-mediated tissue repair. Platelets are cellular mediators that orchestrate clinically relevant but still poorly understood mechanisms of tissue repair. They release cytokines, chemokines, and growth factors such as SDF-1 and HGF that control recruitment, proliferation, and activation of fibroblasts, neutrophils, monocytes, SMCs, MSCs, and other cell types critically involved in wound healing. Platelets also regulate angiogenesis in damaged tissue, which is another important mechanism for recovery of tissue function. Recruitment of progenitor cells, including MSCs, SMCs, endothelial progenitors, and CD34-positive progenitors, is influenced by platelets as well, promoting wound repair at least partially due to paracrine mechanisms. Moreover, platelets are capable of modulating the balance between apoptosis and cell survival, which determines the pathophysiology of damaged tissues. They can release proapoptotic (Fas- $\mathrm{L}$, CD40L, TRAIL, TWEAK, and LIGHT) as well as antiapoptotic (HGF, SDF-1, serotonin, adenosine diphosphate, and SP-1) mediators. Moreover, microparticles derived from platelets can regulate apoptosis in endothelial cells and SMCs as well as provide survival signals to monocytic, endothelial, and neural stem cells. Granzyme B is a mediator of platelet-induced apoptosis in spleen and lung. HMGB1, a danger signal that is exported to the cell surface by platelets upon activation, regulates apoptosis as well as autophagy in tumor cells depending on its redox status. Therefore, platelets control complex mechanisms of tissue repair. ADP, adenosine diphosphate; CD62P, P-selectin; CM, cardiomyocyte; EC, endothelial cell; HGF, hepatocyte growth factor; MØ, macrophage; MP, microparticle; MSC, mesenchymal stem cell; NSC, neural stem cell; pAkt, phosphorylated Akt; PC, progenitor cell; ROS, reactive oxygen species; Ser, serotonin; SDF-1, stromal cell-derived factor-1; SMC, smooth muscle cell; SP-1, sphingosine-1-phosphate; TC, tumor cell; ECM, extracellular matrix. Reused from the article of Gawaz M, et al. (Blood 2013;122:2550-4) [5].

interact with the platelets through cellular expression and excreted components. Further, PRP might also contain other elements such as soluble proteins, hormones, and cell adhesion molecules [5].

The abundant GFs and cytokines stored in the platelet granules can be either naturally released by thrombin activation and 
Table 1. Synopsos of growth factors present in platele-rich plasma

\begin{tabular}{|c|c|c|}
\hline Growth Factor & Source & Function \\
\hline $\begin{array}{l}\text { Transforming growth } \\
\text { factor-beta }\end{array}$ & $\begin{array}{l}\text { Platelets, extracellular matrix of bone, } \\
\text { cartilage matrix, activated TH1 cells } \\
\text { and natural killer cells, macrophages/ } \\
\text { monocytes and neutrophils }\end{array}$ & $\begin{array}{l}\text { Stimulates MSCs proliferation; regulates endothelial, fibroblastic } \\
\text { and osteoblastic mitogenesis; regulates collagen synthesis and } \\
\text { collagenase secretion; regulates mitogenic effects of other growth } \\
\text { factors; stimulates endothelial chemotaxis and angiogenesis; inhibits } \\
\text { macrophage and lymphocyte proliferation }\end{array}$ \\
\hline $\begin{array}{l}\text { Basic fibroblast growth } \\
\text { factor }\end{array}$ & $\begin{array}{l}\text { Platelets, macrophages, MSCs, } \\
\text { chondrocytes, osteoblasts }\end{array}$ & $\begin{array}{l}\text { Promotes growth and differentiation of chondrocytes and osteoblasts; } \\
\text { mitogenetic for MSCs, chondrocytes and osteoblasts }\end{array}$ \\
\hline $\begin{array}{l}\text { Platelet derived growth } \\
\text { factor }\end{array}$ & $\begin{array}{l}\text { Platelets, osteoblasts, endothelial cells, } \\
\text { macrophages, monocytes, smooth } \\
\text { muscle cells }\end{array}$ & $\begin{array}{l}\text { Mitogenetic for MSCs and osteoblasts; stimulates chemotaxis and } \\
\text { mitogenesis in fibroblast/glial/smooth muscle cells; regulates } \\
\text { collagenase secretion and collagen synthesis; stimulates macrophage } \\
\text { and neutrophil chemotaxis }\end{array}$ \\
\hline $\begin{array}{l}\text { Epidermal growth } \\
\text { factor }\end{array}$ & Platelets, macrophages, monocytes & $\begin{array}{l}\text { Stimulates endothelial chemotaxis/angiogenesis; regulates collagenase } \\
\text { secretion; stimulates epithelial/mesenchymal mitogenesis }\end{array}$ \\
\hline $\begin{array}{l}\text { Vascular endothelial } \\
\text { growth factor }\end{array}$ & Platelets, endothelial cells & $\begin{array}{l}\text { Increases angiogenesis and vessel permeability, stimulates mitogenesis } \\
\text { for endothelial cells }\end{array}$ \\
\hline $\begin{array}{l}\text { Connective tissue } \\
\text { growth factor }\end{array}$ & $\begin{array}{l}\text { Platelets through endocytosis from } \\
\text { extracellular environment in bone } \\
\text { marrow }\end{array}$ & $\begin{array}{l}\text { Promotes angiogenesis, cartilage regeneration, fibrosis and platelet } \\
\text { adhesion }\end{array}$ \\
\hline
\end{tabular}

Reused from the article of Everts PA, et al. (J Extra Corpor Technol 2006;38:174-87) [6].

MSC, mesenchymal cells.

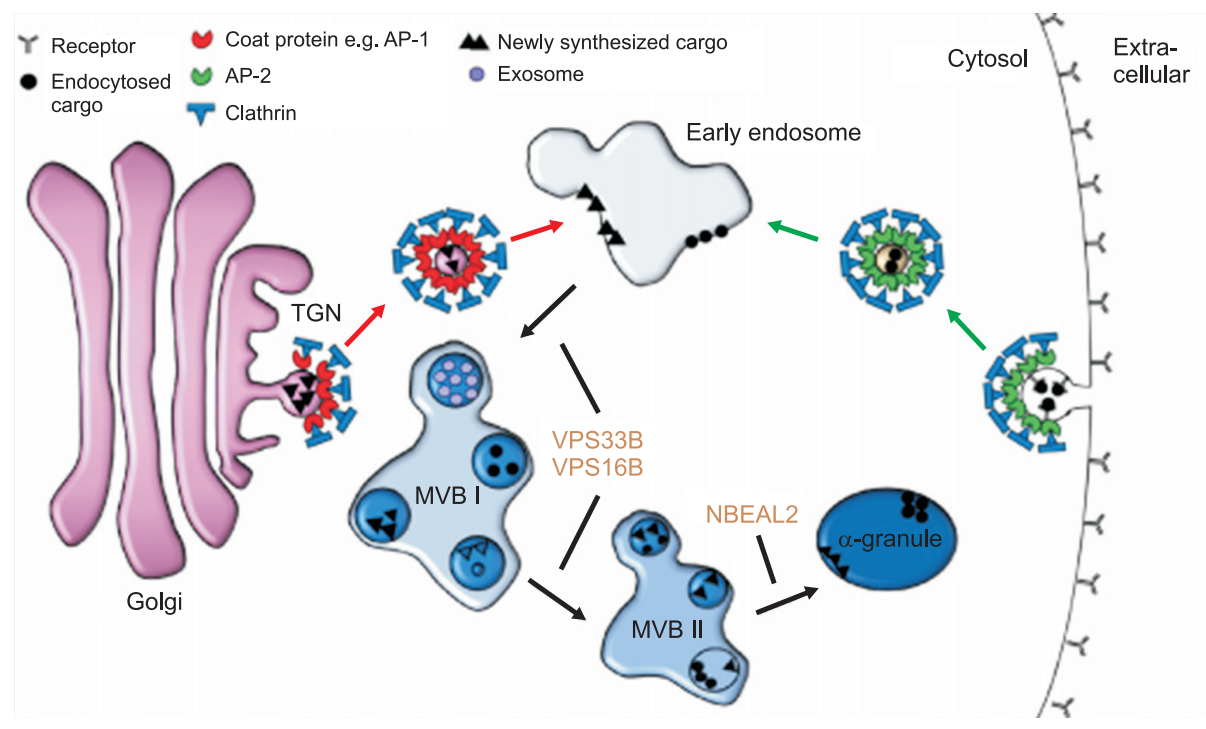

Fig. 3. Working models of platelet $\alpha$-granule formation in megakaryocytes. $\alpha$-granules derive from two major pathways: synthetic and endocytic. The synthetic pathway originates at the trans-Golgi network (TGN). Soluble clathrin molecules recruited to the TGN self-assemble into a lattice structure and interact with coat proteins, presumed to be adaptor protein 1 (AP-1), to form clathrin-coated pits. These pits invaginate to bud off early membrane-bound vesicles that are ultimately directed to early endosomes. Endocytic vesicles originate similarly at the plasma membrane employing adaptor protein 2 (AP-2) and ultimately merge into early endosomes. $\alpha$-granules mature in multivesicular bodies (MVBs), a process that requires proteins Vacuolar Protein Sorting (VPS) 33B, VPS16B, and Neurobeachin Like 2 (NBEAL2). Reused from the article of Sharda A, et al. (F1000Res 2018;7:236) [7].

clotting or artificially by freeze/thaw-mediated platelet lysis, sonication or chemical treatment. For the clinical use in regenerative medicine, autologous PRP collected from peripheral blood has been commonly used with or without ex vivo activation using 3 main activators, collagen, thrombin, and calcium. Thrombin acts significantly faster than calcium (which is usual- ly injected), and calcium is a faster than collagen [17]. Platelets are the first bodies to reach the injured tissue and continuously release GFs throughout their viable period even in the absence of any activator during the clinical procedure. However, once activated, they begin to act within 10 minutes after activation, with more than $95 \%$ of the pre-synthesized GFs secreted within 
1 hour, depending on the PRP preparation technique [18]. Activation by collagen occurs spontaneously when PRP is injected into a soft tissue site [19]. Once the PRP is activated, irrespective of whether the activation is strong or weak or whether the action is occurring in vivo or ex vivo, a fibrin network begins to form. During this process, fibrin supports the tissue scaffold and platelets release their contents over a sustained period. The fibrin fibers, in turn, form networks featuring different architectures, which facilitate release of GFs as well as the adherence, proliferation and differentiation of living cells during tissue regeneration events $[9,10,20]$. If PRP is over-activated, the fibrin will form into a bivalent network that is unstable. In comparison, if the PRP is activated in a more physiological manner, a stable tetra-molecular network forms that enhances the adherence of cells and release of GFs [21]. By understanding the above points, clinicians can select and prepare the adequate form of PRP and select an activator whose strength is appropriate for the clinical purpose (Fig. 4) [9,10,22].

There has been a lot of debate about the role of neutrophil in PRP therapy. It is possible that they may confer an advantage to the patient by reducing the chances of infection or by modulating the inflammatory response [23]. However, when PRP is used for the purpose of regeneration, neutrophils appear to have a deleterious effect on the tissue, resulting in increased inflammation, pain and further scarring as they contain over 40 hydrolytic enzymes and release oxygen-free radicals, catabolic cytokines, matrix metalloproteinases, P-selectin, CD40L, and other pro-inflammatory mediators which can degrade tissue [24]. Nonetheless, WBCs, to some extent, are inevitably present in the usual PRP product.

Autologous PRP or PRP related products are safe and easy to prepare for the point of care, and provide a GF-rich scaffold. Injectable PRP is also easily applicable for combinational use with other scaffolds such as hyaluronic acid and fat grafts $[25,26]$.

\section{Platelet-derived extracellular vesicles, microRNA and cell-free therapy}

Platelets was regarded simply as cellular fragments that can release GFs cargo and have no synthetic capabilities. And, there is lack of understanding about PRP induced tissue repair. Degradation of GFs in vivo can occur via several distinct pathways including denaturation, oxidation and proteolysis. Most of the GFs in platelets, found in the unbound form, have a short life span (minutes to hours). The biological half-life of insulin-like GF-1 in serum is 10 minutes, vascular endothelial growth factor is less than $\mathbf{3 0}$ minutes, and for platelet-derived growth factor

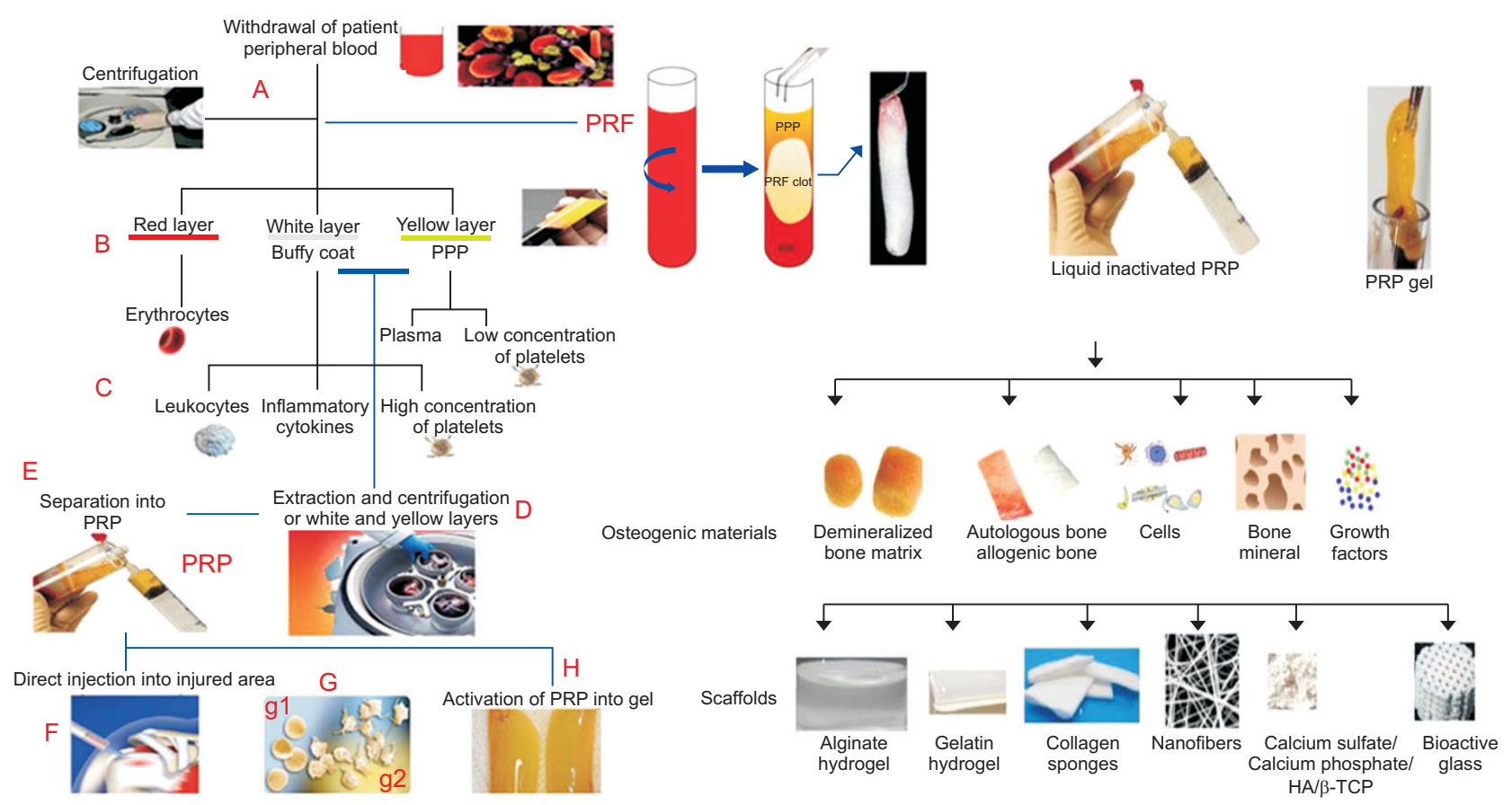

Fig. 4. After centrifuged with anticoagulant (A-D), platelet-rich plasma (PRP) and PRP gel can be acquired. And after centrifuge without anticoagulant, platelet-rich fibrin (PRF) is acquired. PRP can be injected directly into the lesion and, PRP gel and PRF are implanted as mass or modified form. HA/ $\beta$-TCP, hydroxylapatite/ $\beta$-tricalcium phosphate; PPP, plate-poor plasma. Cited from the articles of Moshiri A, et al. (Hard Tissue 2013;2:6) [9]; Masoudi E, et al. (Curr Stem Cell Rep 2016;2:33-42) [10]; Fernandes G, et al. (Bone Res 2016;4:16036) [22]. 


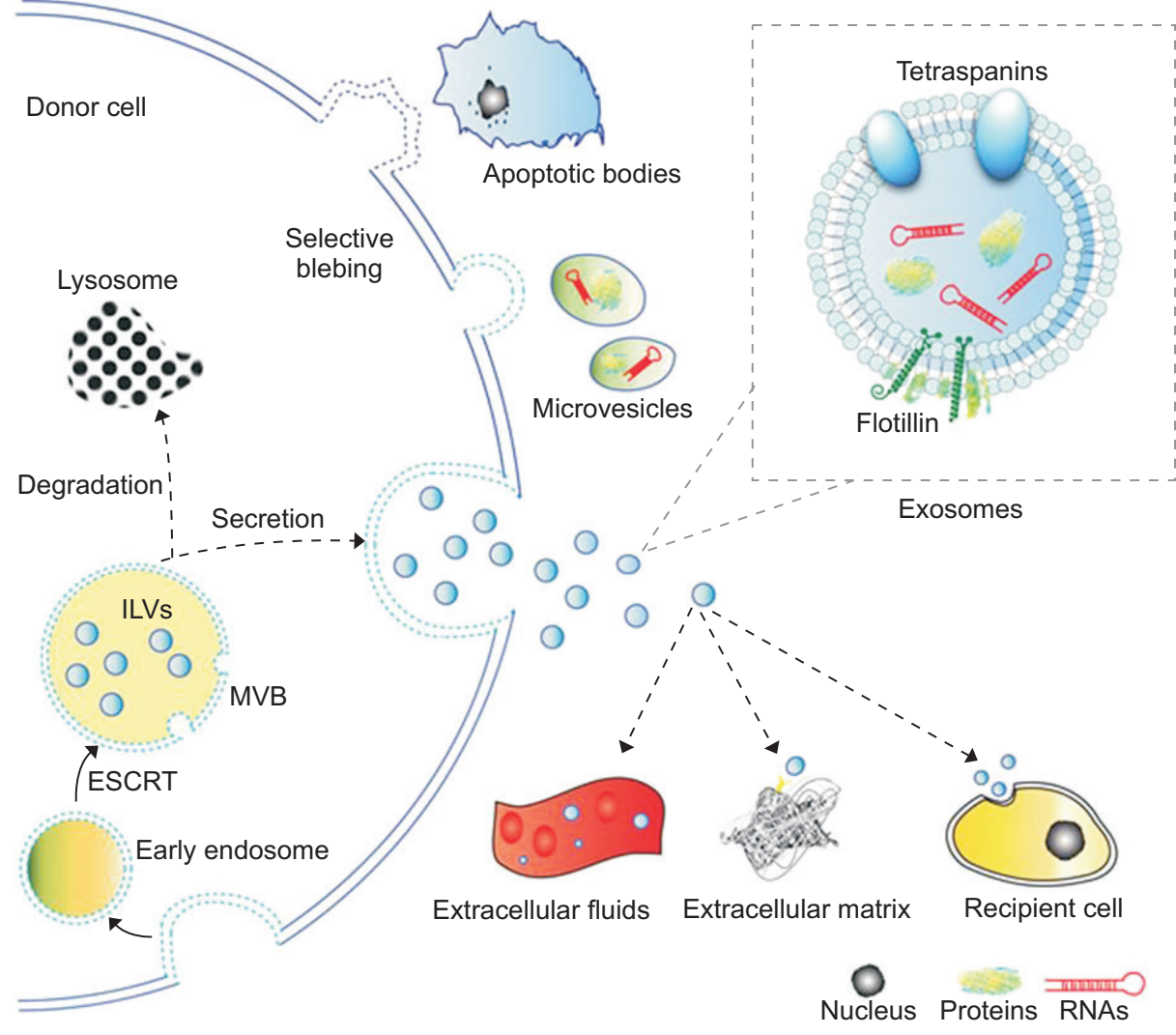

Fig. 5. Schematic representation of the origin, release, and structure of exosomes. Extracellular vesicles, including exosomes (30-100 $\mathrm{nm}$ in diameter) and microvesicles (sometimes called microparticles or ectosomes; 100-1,000 $\mathrm{nm}$ in diameter), exist in almost all biological fluids carrying multifarious molecules such as proteins, lipids, and RNAs either on their surface or within their lumen. They are generated and released from nearly all cell types into the extracellular space. MVB, multi-vesicular body; ILV, intraluminal vesicle; ESCRT, endosomal sorting complex required for transport. and fibroblast growth factor are 2.4 and 7.6 hours, respectively [27]. Subsequent studies revealed that new proteins can be synthesized by platelets [28]. In addition, these studies also suggested that the platelets can actively transfer RNAs to other cells. Among the RNAs, the messenger RNAs incorporated into the target cells can be translated into proteins and microRNAs have been found to regulate gene expression, resulting in functional changes in the target cells [3,29].

As seen in the Fig. 5, platelet-derived extracellular vesicles (p-EVs) carry various cargoes including lipids, anchored membrane receptors, cytosolic proteins such as GFs, proteins transcription factors as well as RNA molecules, including microRNAs. Exosomes originate from the inward budding of the endosomal membrane and are more rigid compared to the others that are formed by the outward budding of the plasma membrane or sequestration [30]. A recent publication suggested a possible coordinated biogenesis between exosomes and microvesicles, and demonstrated that these functions appear either complementary or non-complementary as exosomes respond positively during immune responses and can act as tools for immunotherapy against cancer, whereas microvesicles act as antagonists [31]. Platelet $\alpha$-granules, which are considered to be late endosomes or MVB, release exosomes to the extra- cellular space [7]. A study showed that there are slight timedependent (from 30 minutes to $>3$ hours) increase in total $p$ EVs in the "absence" of an added activator, and the p-EVs of inactivated platelets were more protein-rich compared to those from activated platelets [32]. Exosomes that were isolated from human PL elicited a significant, dose-dependent increase in the cell proliferation and migration of bone marrow MSCs (BMMSCs) and ability of these MSCs to deposit mineralized matrix. Moreover, evaluation of the exosome protein content revealed higher amount of GFs compared to PL [33]. Further, small RNAs were found to be enriched in exosomes as compared to donor platelets. These results suggest that exosomes can consistently contribute to PL activity and can be suitable nano-delivery systems for cell-free regeneration therapies, even though limited than MSC exosomes [34]. However, so far, there are many questions that still need to be addressed for the practical clinical use of exosomes.

\section{Paradigm shift and the current status of platelet-rich plasma therapy in the world}

With increase in the demand for PRP therapy, it is important for clinicians to understand the regulation and the stance of 
their country as well as be up to date with the biological knowledge. With globalization, many countries have included common regulations and audit programs in addition to safety-based common grading systems, irrespective of the differences in the detailed category codes [35]. However, from a medical practice perspective, PRP therapy is still a controversial issue in many ways. Based on scientific breakthroughs, individual countries intend to regulate the medical procedures for using cell-based therapeutics by establishing a new regulatory framework. One of the most notable example is Japan. In November 2014, they enforced a new regulatory framework for regenerative medicine to ensure the complete safety of regenerative medicine and to promote the development of its practical applications. (Fig. 6) $[36,37]$.

PRP therapy is now going through a period of transition as although platelets have been used as transfusion therapeutics for coagulopathies for a long time, they have not been fully utilized for cell-based regenerative therapy for many reasons. The acts for the regulation of PRP devices and medical practice of some countries are compared in Table 2 [38-43]. In the Republic of Korea, devices for PRP preparation have been categorized as Grade III (moderate risk) by Korea Food and Drug Administra- tion and, till June 2019, over 35 PRP kits have been permitted. However, the medical act, which is controlled by the Ministry of Health \& Welfare, indicates that the medical practice of PRP is considered to be illegal except for use as a dental implant adjuvant and aesthetic or for plastic surgery. The reason is that its therapeutic effectiveness has not yet been fully elucidated in order to be included in national health insurance system, even though its safety has already been approved. However, in most other countries, medical practice is at the discretion of clinician under the presumption that they act responsibly as medical personnel.

In Japan, the Ministry of Health, Labour and Welfare (MHLW) classified PRP therapy with/or without activation as Class III (low risk) grade "cell-based therapy", which is defined as low risk therapy involving cells that are subjected to limited manipulation using processes by the Act on the Safety of Regenerative Medicine (ASRM) [43]. However, procedures such as blood transfusion, hematopoietic stem cell transplantation and assisted reproductive technology are excluded from these regulations by government ordinance. Cell-based medical practice such as PRP should be enacted only in licensed facilities in accordance with the licensed standard operating procedures

Regulatory framework for regenerative medicine in Japan

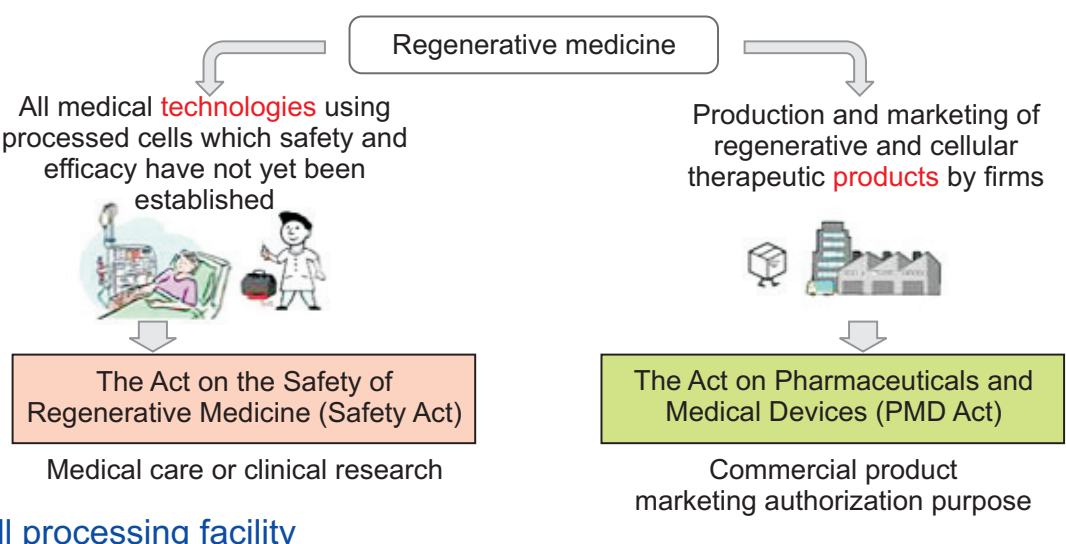

Cell processing facility

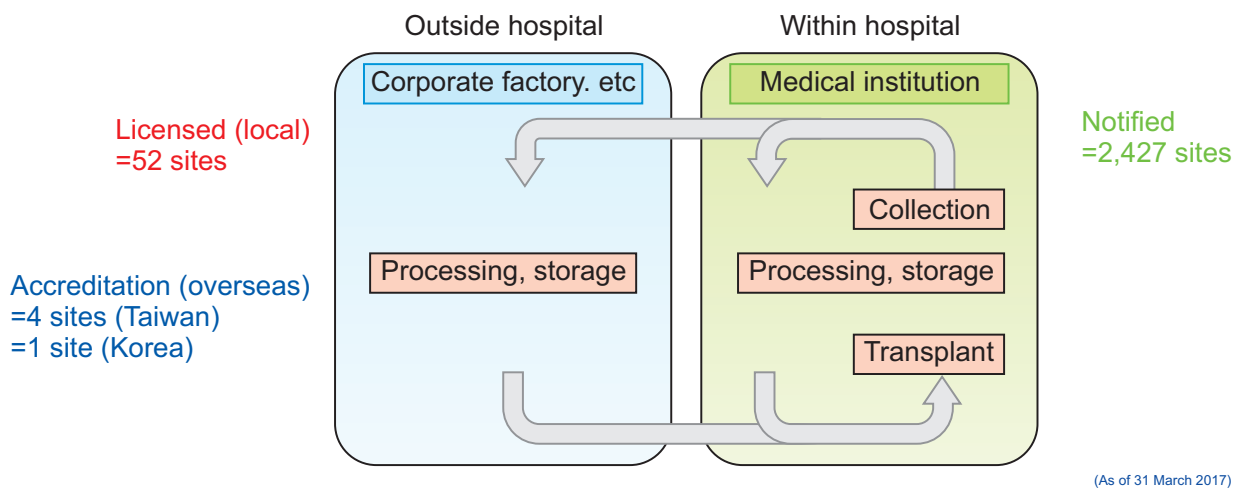

Fig. 6. Japan has enacted three laws to promote the use of regenerative medicine as a national policy. The first law to be enacted was the Regenerative Medicine Promotion Act, which represents the country's determination to work toward the promotion of regenerative medicine, following which the PMD Act and the Act on the Safety of Regenerative Medicine (ASRM) came into effect. Cell Processing Facilities, "places other than medical institutions or outside Japan or medical institutions" should conform to the standards of structure and equipment, and observe the standards of manufacture management, quality control, etc. (Contents of the Standards - Method of manufacturing and quality control of cell products, implementation method of testing and inspection, method of storage, etc.). Cited from Yoshiaki M (https://www. pmda.go.jp/files/000219466.pdf) [37]. 
Table 2. The act and stance for platelet-rich plasma (PRP) devices and medical practice of some countries (June 2019)

\begin{tabular}{|c|c|c|}
\hline Country & PRP device (risk base grade and classification) & PRP medical act \\
\hline \multicolumn{2}{|c|}{$\begin{array}{c}\text { Republic of } \bullet \text { Class III (moderate risk) (I-IV) } \\
\text { Korea } \\
\bullet \\
\text { treatment of the extracted blood to re-inject into the body. } \\
\text { It includes a container for centrifugation, blood transfusion } \\
\text { set, and syringe } \\
\bullet \text { Over } 35 \text { ready-made PRP kit [39] are apprived in Korea }\end{array}$} & $\begin{array}{l}\text { - Illegal except for aesthetic or plastic surgery purpose and } \\
\text { adjuvant use for dental implant [38] }\end{array}$ \\
\hline U.S [40] & $\begin{array}{l}\text { - Class II (low-moderate risk) (I-III) } \\
\text { - } 21 \text { CFR } 864.9245 \text { as Automated blood cell separator-the } \\
\text { devices intended to be used to mix with bone graft materials } \\
\text { to enhance bone graft handling properties in orthopedic } \\
\text { practices-should be approved with under a } 510(\mathrm{k}) \text { pre- } \\
\text { market notification submit } \\
\text { - No ready-made kits made in Rep. of Korea are approved as } \\
510 \text { (k) [41] }\end{array}$ & $\begin{array}{l}\text { - PRP is included in HCT/Ps (human cells, tissues, and } \\
\text { cellular and tissue-based products) and it is under control of } \\
\text { the FDA's } 21 \text { CFR } 1271 \text { of the Code of Regulations } \\
\text { - Free to use a PRP product by Section } 361 \text { of the Public } \\
\text { Health Service Act-commonly used in the field of dental, } \\
\text { orthopedics, plastic surgery as well as office injection for } \\
\text { wound and cosmetic purpose, and etc. }\end{array}$ \\
\hline China & $\begin{array}{l}\text { - Class III (moderate high-high) (I-III) } \\
\text { - MD code 10-02-08: } \\
\text { 10: Transfusion, Hemodialysis, Extracorporeal circulation } \\
\text { 02: Blood separation, processing, storage equipment } \\
\text { 08: Preparation of autologous platelet-rich plasma from } \\
\text { human autologous blood samples } \\
\text { - Only } 3 \text { ready-made PRP kits are approved as Class III }\end{array}$ & $\begin{array}{l}\text { - Medical institutions permitted by government may use } \\
\text { approved ready-made PRP kit to serve their own clinical } \\
\text { needs, and use them within their own institution under the } \\
\text { guidance of licensed medical practitioners }\end{array}$ \\
\hline Japan [43] & \multicolumn{2}{|c|}{ Both PRP processing and medical act are controlled under Regenerative Medicine Promotion Act (from November 2014) } \\
\hline
\end{tabular}

(SOP) based on the concepts of GMP. Therefore, those facilities should be qualified to ensure the safety and efficacy of the devices. Therefore, inside a medical institution, clinicians may use specially controlled ready-made PRP processing kits approved by the MHLW (class III and IV grade generic name as for medical device classification) or home-made protocols using lower grade devices after due notification to the MHLW. According to a report by Kawase and Okuda [43], some groups of clinicians use devices which are not for the preparation of implantable blood-derived materials or low quality devices as the verification for autologous PRP therapy is somewhat lax due to the assumption that it is the safest cell-based therapy. They claimed that clinicians should choose products manufactured in accor- dance with reliable quality systems of manufacturing. Actually, MHWL has increased the regulatory pressure for safety and efficiency for that. So far, only two PRP kits, TriCell (REV-MED Inc., Seongnam, Korea; approval number, 22900BZX00068000) and GPS III (Zimmer Biomet Inc., Warsaw, IN, USA; approval number, 22700BZX00420000), have verified their PRP products through certification of analysis and have been approved as Class III medical devices in Japan [44].

\section{Consensus about nomenclature and classification system}

It is very difficult to sort and interpret the published clinical or research data about PRP therapy due to the complicated no- 
menclatures and classification system. This is one of the main reasons that hinders the establishment of PRP therapy, in spite of the presence of many reported clinical results related to this. The nomenclature by Dohan Ehrenfest et al. [45], who classified PRP into four main categories (P-PRP, L-PRP, P-platelet-rich fibrin [P-PRF], L-PRF) depending on their leucocyte and fibrin content, is recommended. This classification system has been largely cited, advocated, and validated by multi-disciplinary consensus conferences. It is recommended that clinicians and researchers use universal generic terminology rather vendor names for PRP to ensure the precise comparison of their clinical outcomes.

\section{Quality management for effective platelet- rich plasma therapy}

\section{Check points for quality assured autologous platelet- rich plasma therapy}

For the achievement of satisfactory clinical results, factors such as control of human influence, PRP preparation protocol and devices, verification of PRP products, medical procedures used by clinicians, and the follow-up treatment procedures should be standardized and maintained [43,46]. The influencing factors and check lists are listed in (Table 3-5) [40,43,47-52]. All the information has been collected on a quality assurance sheet to document the reason for seeking injection, adverse events, and the immediate outcome.

\section{Selection guideline for platelet-rich plasma devices}

The most important considerations during the preparation of PRP are safety and effectiveness for human tissue regeneration. Recently, there have been suggestions that there should be more emphasis on the quality testing of final PRP products rather than the preparation protocol and devices to support strong therapeutic evidence [53]. However, these tests are expensive, time-consuming and cumbersome for clinical procedures. Simple tests have been proposed although their validity needs to be further verified. Although most clinicians prefer readymade kits for many reasons, there are too many variations in their specifications such as recovery rate, concentration performance, RBC and WBC content, the volume of drawn blood, centrifuge condition and the time required.

Therefore, we have made a suggestion that will enable clinicians to select the appropriate commercial kit. First of all, kits

Table 3. Recommended check lists for pre-procedure of autologous platelet-rich plasma (PRP) therapy [43]

(1) Contraindication

- Cancer or cancer with metastatic state, especially hematologic malignancy

- Platelet disorder in function and number - Thrombocytopenia $\left(<10^{5} / \mu \mathrm{l}\right)$, platelet dysfunction syndrome etc.

- Hemodynamic instability or hematologic disorder - anemia $(\mathrm{Hb}<10 \mathrm{~g} / \mathrm{dl})$

- Hypofibrinogenemia, Coagulopathies, Septicemia

- Active infection with Pseudomonas, Klebsiella, or Enterococcus

- Pregnancy or active breastfeeding

- Skin lesions in the area of the injection

- Medication affect platelets activation [47] - The time limits of drug administration prior to procedure is: Nonsteroidal anti-inflammatory drugs (NSAID), up to 48 hours; aspirin (ASA) or ASA-containing drug and Warfarin, 7 days; low dose Heparin 12 hours heparins; systemic Corticosteroids, 2 weeks; Corticosteroid injection at treatment site within 1 month.

- Disorders and conditions affect platelets activation and PRP preparation

- Type 2 diabetes mellitus, Life habits (alcohol and smoking), Diet (fasting for 3 hours is recommended to prevent plasma opacity and viscosity), Diet (Garlic), etc.

(2) Recommended basic blood test for platelets - Platelet count, platelet function or aggregation test, prothrombin time, thrombin time, and coagulation time

(3) Recommended laboratory test to evaluate general condition and rule out contraindications - efficacy and clinical outcomes largely dependent on a patient's conditions (CBC, LFT, aPTT, BT), Liver Function Test, Diabetes Test, Lipid profile, Thyroid Function Test, Renal Function Test, Inflammation marker (ESR, CRP), Tumor markers, Uric acid, Folic acid, Vitamin $\mathrm{B}_{12}$ and Routine Urinalysis, Tracking of Infection if have, Bone metabolism marker (Vitamin D, Parathyroid Hormone, Growth Hormone) if PRP is used for bone graft adjuvant - Platelet indices in CBC profile shows platelet size variation and production status

- The cholesterol or uric acid crystals in plasma induce aggregation and pre-activation of platelet and affect to tissue healing process at injured site

(4) Informed consent and patients instruction

- Risks to patient from the procedure should be noticed: infection, bleeding, nerve damage, pain, unsatisfactory result and complications associated with accompanying operations, regulatory issues, process, efficacy and clinical outcomes, etc.

- Allow the patient to make an informed decision

CBC, complete blood count; LFT, liver function tests; aPTT, activated partial thromboplastin time; BT, bleeding time; ESR, erythrocyte sedimentation rate; $\mathrm{CRP}, \mathrm{C}$-reactive protein. 
Table 4. Recommend check lists for platelet-rich plasma (PRP) preparing procedure for point-of-care use [43]

- Blood collection, storage and handling

- Recommend 19-21 gauge needle with a free-flowing technique to prevent platelet activation

- Disinfect in phlebotomy site (Betadine can be used for donor site but it should be wiped and completely dried)

- If the vein collapses or there is stoppage of blood flow during collection, the blood should be discarded and a venipuncture should be repeated from another site and the plasma showing grossly hemolyzed or turbid should be rejected

- Platelet should be handled at room temperature $\left(22^{\circ} \mathrm{C} \pm 4^{\circ} \mathrm{C}\right)$ and every step in handling of kit should not be delayed

- Anticoagulant

- ACD is preferred because EDTA and heparin induce platelet aggregation, and EDTA can damage the platelet membrane

- Blood is collected in the syringe containing ACD solution with mixing rate 10:1.5 in volume. Usually, about $2 \mathrm{ml}$ of PRP can be acquired from the total volume of $10 \mathrm{ml}$

- If the patients want prolotherapy together, $3.2 \%$ of sodium citrate in 9:1 volume should be used because ACD solution may increase of glucose in PRP

- Another collection of blood without anticoagulant and sterile medical devices should be prepared if platelet-rich fibrin (PRF) is prepared

- Manufacturing of autologous PRP using ready-made kits

- Select highly verified and certified kits

- Preference is given to a closed system that prevents exposure of the blood and cellular components to the open air in the room

- The performance and sterility of all devices and materials should be maintained and checked regularly and those should be documented - Acquired PRP product should be verified, at least, about the volume, platelet content, WBC content and pH

- Preparation of autologous thrombin and activated PRP gel (Fig. 4)

The blood is collected without anticoagulant and centrifuged for 10 minutes at $500 \times \mathrm{g}$ using permitted devices. After centrifugation, 0.8 $\mathrm{ml}$ of the serum is corresponds to the autologous thrombin. Add thrombin in the proportion of $0.8 \mathrm{ml}$ of thrombin for $4 \mathrm{ml}$ of PRP and/ or $0.4 \mathrm{ml}$ of calcium gluconate $(9.3 \mathrm{mg} / \mathrm{ml})$ is added for final $4 \mathrm{ml}$ of PRP $(10 \%)$. Activation should be carried out immediately before the application (calcium chloride is not recommended because it is known that induce tissue necrosis), and use permitted devices and drugs which are different between the countries

- Production of PRF [48]

After centrifuge of venous blood without anticoagulant, middle fraction containing the fibrin clot is then collected. The devices should be permitted as medical devices for preparation of implantable blood-derived materials

ACD, acid citrate dextrose; EDTA, ethylenediaminetetraacetic acid.

Table 5. Check lists for platelet-rich plasma (PRP) application and follow up [40]

(1) All the procedure should be carried out with sterile materials and in aseptic field

(2) The maximum time period between the blood collection and application should not exceed 1 hour

(3) The mapping the injection point and injection amount should be recorded by photograph or drawing if patients deny it. Sometimes, before surgery, diagnostic imaging studies are helpful

(4) As for recipient area, Betadine is not preferred disinfectant because of its cytotoxic effect. Lidocaine, ropivacine, and/or epinephrine are preferred as local anesthetics. Bupivacaine should be avoided if inject muscular or periosteal depth because it can be toxic to chondrocytes [49]. Up to $30 \mathrm{G}$ with $51 \mathrm{~mm}$ needles proved that not affect platelet function and growth factors [50]. More decreased diameter and longer of needle make higher shear and extensional forces

(5) The patient is placed in an appropriate and comfortable position that allows for sterility and access to the site of injection. All necessary materials for the injection should have been planned and placed on a sterile table adjacent and easily accessible to the physician

(6) After procedure, patients should be given post-procedure instructions, precautions, and emergency contact information

(7) Patients should be monitored for post-procedure complications and generally re-examined 12 weeks after the procedure to follow up [51] Complications, patient's response and all other pertinent data should be recorded for evaluation. For the research, recipient data is also collected at $3,6,12$, and 24 months or more

(8) There are no general rule but the number of application is usually maintained during 3 months, at 15 days or monthly intervals [52]. For post-surgical recovery, PRP might be injected three to six time additionally

(9) All of them should be documented and surveilled.

with the verified features for the final product, such as platelet concentration and GFs contents, should be selected. The next important factor is the RBC contamination [13]. Following that, the subsequent factor that should be considered is the WBC concentration in the final PRP. When the platelets are highly concentrated, there are greater chances of an increase in the number of WBCs, which results in higher chances of destruction or pre-activation of the platelets. If clinicians prefer the combinational approach for immune modulation, kits with flexible WBC content are advantageous. The type of anticoagulant, the draw blood volume and the final volume of PRP should be adjustable to suit the clinical purpose. The handling time and 
centrifugation specifications are also other influencing factors. The kits and centrifuges should be easy to operate, ergonomically comfortable, and economically appropriate.

Finally, irrespective of the choice of device or method, care should be taken to keep the platelet count in the prepared PRP within the recommended limits as a minimum check point is required to assure efficacy.

\section{Conclusion}

In the field of cosmetic and reconstructive medicine, PRP has been used as a source of abundant GFs and scaffolding. Recently, the role of PRP in stimulating tissue regeneration has been demonstrated, which has made it a suitable candidate as a bioengineering material. To use PRP as an effective regenerative material, clinicians need to be well informed about its essential physiological role as well as the quality assurance procedure.

\section{Conflicts of interest}

The authors have nothing to disclose.

\section{References}

1. Crane D, Everts PAM. Platelet ich Plasma (PRP) matrix grafts. Pract Pain Manag 2008;8:11-26.

2. Neumüller J, Ellinger A, Wagner T. Transmission electron microscopy of platelets from apheresis and buffy-coat-derived platelet concentrates. In: Maaz K, editor. The transmission electron microscope - theory and applications. London: IntechOpen Limited; 2015. p. 255-84.

3. Dangwal S, Thum T. MicroRNAs in platelet biogenesis and function. Thromb Haemost 2012;108:599-604.

4. van der Meijden PEJ, Heemskerk JWM. Platelet biology and functions: new concepts and clinical perspectives. Nat Rev Cardiol 2019;16:166-79.

5. Gawaz M, Vogel S. Platelets in tissue repair: control of apoptosis and interactions with regenerative cells. Blood 2013;122: 2550-4.

6. Everts PA, Knape JT, Weibrich G, Schönberger JP, Hoffmann J, Overdevest EP, et al. Platelet-rich plasma and platelet gel: a review. J Extra Corpor Technol 2006;38:174-87.

7. Sharda A, Flaumenhaft R. The life cycle of platelet granules. F1000Res 2018;7:236.

8. Strunk D, Lozano M, Marks DC, Loh YS, Gstraunthaler G, Schennach $\mathrm{H}$, et al. International Forum on GMP-grade hu- man platelet lysate for cell propagation: summary. Vox Sang 2018;113:80-7.

9. Moshiri A, Oryan A. Role of platelet-rich plasma in soft and hard connective tissue healing: an evidence-based review from basic to clinical application. Hard Tissue 2013;2:6.

10. Masoudi E, Ribas J, Kaushik G, Leijten J, Khademhosseini A. Platelet-rich blood derivatives for stem cell-based tissue engineering and regeneration. Curr Stem Cell Rep 2016;2:33-42.

11. Weibrich G, Kleis WK, Hafner G, Hitzler WE. Growth factor levels in platelet-rich plasma and correlations with donor age, sex, and platelet count. J Craniomaxillofac Surg 2002;30:97102.

12. Marx RE. Platelet-rich plasma (PRP): what is PRP and what is not PRP? Implant Dent 2001;10:225-8.

13. Knezevic NN, Candido KD, Desai R, Kaye AD. Is plateletrich plasma a future therapy in pain management? Med Clin North Am 2016;100:199-217.

14. 5.7.4.20 Platelets. The proposed 32nd edition of standards for blood banks and transfusion services. Bethesda (MD): American Association of Blood Banks; 2019.

15. Purita J. The use of PRP injections and stem cells in an office setting. In: Lana JFSD, Santana MHA, Belangero WD, Luzo ACM, editors. Platelet-rich plasma: regenerative medicine: sports medicine, orthopedic, and recovery of musculoskeletal injuries. Heidelberg: Springer; 2014. p. 171-86.

16. Hooiveld M, Roosendaal G, Wenting M, van den Berg M, Bijlsma J, Lafeber F. Short-term exposure of cartilage to blood results in chondrocyte apoptosis. Am J Pathol 2003;162:94351.

17. Roussy Y, Bertrand Duchesne MP, Gagnon G. Activation of human platelet-rich plasmas: effect on growth factors release, cell division and in vivo bone formation. Clin Oral Implants Res 2007;18:639-48.

18. Sánchez-González DJ, Méndez-Bolaina E, Trejo-Bahena NI. Platelet-rich plasma peptides: key for regeneration. Int J Pept 2012;2012:532519.

19. Di Matteo B, Filardo G, Kon E, Marcacci M. Platelet-rich plasma: evidence for the treatment of patellar and Achilles tendinopathy--a systematic review. Musculoskelet Surg 2015;99:19.

20. Perez AG, Rodrigues AA, Luzo AC, Lana JF, Belangero WD, Santana MH. Fibrin network architectures in pure plateletrich plasma as characterized by fiber radius and correlated with clotting time. J Mater Sci Mater Med 2014;25:1967-77.

21. Italiano JE Jr, Richardson JL, Patel-Hett S, Battinelli E, Zaslavsky A, Short S, et al. Angiogenesis is regulated by a 
novel mechanism: pro- and antiangiogenic proteins are organized into separate platelet alpha granules and differentially released. Blood 2008;111:1227-33.

22. Fernandes G, Yang S. Application of platelet-rich plasma with stem cells in bone and periodontal tissue engineering. Bone Res 2016;4:16036.

23. Fitzpatrick J, Bulsara MK, McCrory PR, Richardson MD, Zheng $\mathrm{MH}$. Analysis of platelet-rich plasma extraction: variations in platelet and blood components between 4 common commercial kits. Orthop J Sports Med 2017;5:2325967116675272.

24. Kaplan MJ, Radic M. Neutrophil extracellular traps: doubleedged swords of innate immunity. J Immunol 2012;189:2689-95.

25. Modarressi A. Platlet rich plasma (PRP) improves fat grafting outcomes. World J Plast Surg 2013;2:6-13.

26. Russo F, D'Este M, Vadalà G, Cattani C, Papalia R, Alini M, et al. Platelet rich plasma and hyaluronic acid blend for the treatment of osteoarthritis: rheological and biological evaluation. PLoS One 2016;11:e0157048.

27. Roh YH, Kim W, Park KU, Oh JH. Cytokine-release kinetics of platelet-rich plasma according to various activation protocols. Bone Joint Res 2016;5:37-45.

28. Schwertz H, Rowley JW, Tolley ND, Campbell RA, Weyrich AS. Assessing protein synthesis by platelets. Methods Mol Biol 2012;788:141-53.

29. Xia L, Zeng Z, Tang WH. The role of platelet microparticle associated microRNAs in cellular crosstalk. Front Cardiovasc Med 2018;5:29.

30. Borges FT, Reis LA, Schor N. Extracellular vesicles: structure, function, and potential clinical uses in renal diseases. Braz J Med Biol Res 2013;46:824-30.

31. Record M, Silvente-Poirot S, Poirot M, Wakelam MJO. Extracellular vesicles: lipids as key components of their biogenesis and functions. J Lipid Res 2018;59:1316-24.

32. Tao SC, Guo SC, Zhang CQ. Platelet-derived extracellular vesicles: an emerging therapeutic approach. Int J Biol Sci 2017;13:828-34.

33. Aatonen MT, Öhman T, Nyman TA, Laitinen S, Grönholm M, Siljander PRM. Isolation and characterization of platelet-derived extracellular vesicles. J Extracell Vesicles 2014;3:24692.

34. Torreggiani E, Perut F, Roncuzzi L, Zini N, Baglìo SR, Baldini N. Exosomes: novel effectors of human platelet lysate activity. Eur Cell Mater 2014;28:137-51; discussion 151.

35. U.S. Food \& Drug Administration. International Medical Device Regulators Forum (IMDRF) [Internet]. Silver Spring (MD): U.S. Food \& Drug Administration; c2019 [cited 2019 Feb 1]. Available from: https://www.fda.gov/medical-devices/international-pro- grams/international-medical-device-regulators-forum-imdrf.

36. Tobita M, Konomi K, Torashima Y, Kimura K, Taoka M, Kaminota M. Japan's challenges of translational regenerative medicine: act on the safety of regenerative medicine. Regen Ther 2016;4:78-81.

37. Yoshiaki M. Regulation of regenerative medicine in Japan [Internet]. Tokyo: Pharmaceuticals and Medical Devices Agency; c2019 [cited 2019 Feb 1]. Available from : https://www.pmda. go.jp/files/000219466.pdf.

38. Implant+sinus lift with PRP, PRF, bone [Internet]. Seoul: Center For New Health Technology Assessment; c2019 [cited 2019 Feb 1].Available from: https://nhta.neca.re.kr/nhta/eng/nhtaENG0501L.ecg.

39. Ministry of Food and Drug Safety. List of blood separation kit medical device [Internet]. Cheongju: Ministry of Food and Drug Safety; c2019 [cited 2019 Feb 1]. Available from: https:// emed.mfds.go.kr/\#!CECAB01F010.

40. Beitzel K, Allen D, Apostolakos J, Russell RP, McCarthy MB, Gallo GJ, et al. US definitions, current use, and FDA stance on use of platelet-rich plasma in sports medicine. J Knee Surg 2015;28:29-34.

41. U.S. Food \& Drug Administration. Complete list of substantially equivalent $510(\mathrm{k})$ device applications [Internet]. Silver Spring (MD): U.S. Food \& Drug Administration; c2019 [cited 2019 Feb 1]. Available from: https://www.fda.gov/media/ $76393 /$.

42. Fiorentino S, Roffi A, Filardo G, Marcacci M, Kon E. European definitions, current use, and EMA stance of platelet-rich plasma in sports medicine. J Knee Surg 2015;28:51-4.

43. Kawase T, Okuda K. Comprehensive quality control of the regenerative therapy using platelet concentrates: the current situation and prospects in Japan. Biomed Res Int 2018;2018: 6389157.

44. Pharmaceuticals and Medical Devices Agency of Japan. Search of medical devices information [Internet]. Kasumigaseki: Pharmaceuticals and Medical Devices Agency of Japan; c2019 [cited 2019 Feb 1]. Available from: https://www.pmda. go.jp/PmdaSearch/kikiSearch/.

45. Dohan Ehrenfest DM, Bielecki T, Mishra A, Borzini P, Inchingolo F, Sammartino G, et al. In search of a consensus terminology in the field of platelet concentrates for surgical use: platelet-rich plasma (PRP), platelet-rich fibrin (PRF), fibrin gel polymerization and leukocytes. Curr Pharm Biotechnol 2012; 13:1131-7.

46. Kawase T, Takahashi A, Watanabe T, Tsujino T. Proposal for point-of-care testing of platelet-rich plasma quality. Int J 
Growth Factors Stem Cells Dent 2019;2:13-7.

47. Liumbruno GM, Bennardello F, Lattanzio A, Piccoli P, Rossetti G; Italian Society of Transfusion Medicine and Immunohaematology (SIMTI) Working Party. Recommendations for the transfusion management of patients in the peri-operative period. I. The pre-operative period. Blood Transfus 2011;9:1940.

48. Kobayashi M, Kawase T, Okuda K, Wolff LF, Yoshie H. In vitro immunological and biological evaluations of the angiogenic potential of platelet-rich fibrin preparations: a standardized comparison with PRP preparations. Int J Implant Dent 2015;1: 31.

49. Lanza F, Beretz A, Stierlé A, Hanau D, Kubina M, Cazenave JP. Epinephrine potentiates human platelet activation but is not an aggregating agent. Am J Physiol 1988;255:H1276-88.

50. Bausset O, Magalon J, Giraudo L, Louis ML, Serratrice N,
Frere C, et al. Impact of local anaesthetics and needle calibres used for painless PRP injections on platelet functionality. Muscles Ligaments Tendons J 2014;4:18-23.

51. Fife CE, Eckert KA, Carter MJ. Publicly reported wound healing rates: the fantasy and the reality. Adv Wound Care (New Rochelle) 2018;7:77-94.

52. Huber SC, Montalvão SADL, Sachetto Z, De Paula EV, Annichino-Bizzacchi JM. Autologous platelet rich plasma (PRP) provoke immunomodulatory response by an increase of regulatory T cells (CD4+ CD25+ FOXP3+) with a decrease of activated NK cells (CD16+ CD56+ CD69+) in a longitudinal study of patients with BehçEt's disease. Blood 2016;128:3849.

53. Mumford AD, Frelinger AL 3rd, Gachet C, Gresele P, Noris $P$, Harrison $\mathrm{P}$, et al. A review of platelet secretion assays for the diagnosis of inherited platelet secretion disorders. Thromb Haemost 2015;114:14-25. 